\title{
First-in-human study assessing safety, tolerability, and pharmacokinetics of 2- hydroxybenzylamine acetate, a selective dicarbonyl electrophile scavenger, in healthy volunteers
}

Lisa M. Pitchford ${ }^{1 *}$ D, John A. Rathmacher, ${ }^{1,2}$, John C. Fuller Jr ${ }^{1}$, J. Scott Daniels ${ }^{3}$, Ryan D. Morrison ${ }^{3}$, Wendall S. Akers ${ }^{4,5}$, Naji N. Abumrad ${ }^{6}$, Venkataraman Amarnath ${ }^{7}$ Patricia M. Currey ${ }^{7}$, L. Jackson Roberts ${ }^{5,8}$, John A. Oates ${ }^{5,8}$ and Olivier Boutaud ${ }^{5}$

\begin{abstract}
Background: 2-Hydroxybenzylamine (2-HOBA) is a selective scavenger of dicarbonyl electrophiles that protects proteins and lipids from being modified by these electrophiles. It is currently being developed for use as a nutritional supplement to help maintain good health and protect against the development of conditions associated with dicarbonyl electrophile formation, such as the cognitive decline associated with Mild Cognitive Impairment and Alzheimer's disease.

Methods: In this first-in-human study, the safety, tolerability, and pharmacokinetics of six ascending single oral doses of 2-HOBA acetate were tested in eighteen healthy human volunteers.

Results: Reported adverse events were mild and considered unlikely to be related to 2-HOBA. There were no clinically significant changes in vital signs, ECG recordings, or clinical laboratory parameters. 2-HOBA was fairly rapidly absorbed, with a $t_{\max }$ of $1-2 h$, and eliminated, with a $t_{1 / 2}$ of approximately $2 h$. Both $t_{\max }$ and $t_{1 / 2}$ were independent of dose level, while $C_{\max }$ and AUC increased proportionally with dose level.
\end{abstract}

Conclusions: 2-HOBA acetate was safe and well-tolerated at doses up to $825 \mathrm{mg}$ in healthy human volunteers, positioning it as a good candidate for continued development as a nutritional supplement.

Trial registration: This study is registered at ClinicalTrials.gov (NCT03176940).

Keywords: Safety, Pharmacokinetics, Humans, Salicylamine, $y$-Ketoaldehydes

\section{Background}

Inflammation and oxidative stress, which have been implicated as potential mediators in the development and progression of many conditions, result in the formation of extremely reactive dicarbonyl electrophiles. These dicarbonyls react with lysine residues to form protein adducts that can alter the function and interactions of various cellular proteins $[1,2]$. Proteins adducted by one

* Correspondence: pitchford@mti-hmb.com

${ }^{1}$ Metabolic Technologies, Inc., Ames, IA 50010, USA

Full list of author information is available at the end of the article such highly reactive dicarbonyl, isolevuglandin, are found at elevated levels in a number of health conditions, including Alzheimer's disease [3], atherosclerosis [4], hypertension [5], and liver disease [6]. Dicarbonyl electrophiles also have been mechanistically associated with the development of Alzheimer's disease, as they have been shown to enhance the oligomerization and neurotoxicity of amyloid beta $[7,8]$.

Fortunately, dicarbonyl electrophiles can be specifically neutralized by a novel class of scavenger molecules [9]. One of these scavenger molecules, 2-hydroxybenzylamine

(c) The Author(s). 2019 Open Access This article is distributed under the terms of the Creative Commons Attribution 4.0 International License (http://creativecommons.org/licenses/by/4.0/), which permits unrestricted use, distribution, and reproduction in any medium, provided you give appropriate credit to the original author(s) and the source, provide a link to the Creative Commons license, and indicate if changes were made. The Creative Commons Public Domain Dedication waiver (http://creativecommons.org/publicdomain/zero/1.0/) applies to the data made available in this article, unless otherwise stated. 
(2-HOBA), reacts substantially faster with these dicarbonyls than does lysine, preventing dicarbonly-associated protein modifications. 2-HOBA, which is naturally found in buckwheat [10], is orally available [11] and crosses the blood brain barrier, resulting in brain 2-HOBA levels approximately twice as high as plasma levels [11]. Administration of 2-HOBA prevented the age-associated working memory deficit in the hApoE4 mouse model [12], suggesting this inhibition of dicarbonyl protein modification could help maintain hippocampal function.

A series of preclinical safety studies, including acute and short-term rodent studies [13] as well as in vitro safety pharmacology studies [14] and sub-chronic rat [15] and rabbit studies [16] indicated no toxicity concerns of 2-HOBA acetate within the therapeutic dose range. Thus, the objective of the present investigation was to perform the initial evaluation of 2-HOBA acetate in humans. This first-in-human study assessed the safety, tolerability, and pharmacokinetics of single ascending doses of 2-HOBA acetate in healthy humans.

\section{Methods}

This study is registered at ClinicalTrials.gov (NCT031 76940). The study protocol was approved by the Vanderbilt University Institutional Review Board. All participants provided written informed consent before participating in the study.

\section{Subjects}

Healthy male and non-pregnant female volunteers over 18 years of age were eligible to participate. Subjects were not permitted to take any medications 2 weeks prior to or during the study. Exclusion criteria included known cardiac, kidney, or hepatic disease; presence of diseases that could manifest morbidity or symptoms/signs that could confound interpretation of the study results; the need to discontinue any drug administered as standard of care treatment; and the unwillingness or inability to use approved birth-control methods.

\section{Compound}

2-HOBA (as the acetate salt, CAS 1206675-01-5) was obtained from TSI (China) Co., Ltd. (Shanghai, China). A commercial production lot was used (Lot 16120312). Our laboratory verified the purity of the commercial lot to be $>99 \%$ via HPLC and NMR spectroscopy. Hard gel capsules (Capsugel, Jiangsu, China) containing 50, 110, and $412.5 \mathrm{mg}$ of 2-HOBA acetate (corresponding to 34 , 75 , and $281 \mathrm{mg} 2$-HOBA) were prepared by TSI (China) Co., Ltd. Determinations of average fill weight, uniformity of weight, disintegration, 2-HOBA content, acetate content, and microbial and analytical tests were within all specification limits.

\section{Study design}

This study was an open-label, single ascending dose study designed to assess pharmacokinetics, safety, and tolerability of single doses of 2-HOBA acetate. A $3+3$ clinical trial design with a modified Fibonacci sequence dosing scheme [17] was used with a starting dose of 50 mg; thereafter, dosages were increased to 100, 200, 330, 550 , and $825 \mathrm{mg}$. These doses of 2-HOBA acetate correspond to 34, 68, 136, 224, 373, and $560 \mathrm{mg} 2$-HOBA. Each dose escalation was initiated only after reviewing safety data from all subjects receiving the previous dose.

Subjects were admitted to the Vanderbilt University Clinical Research Center and remained on the unit for $24 \mathrm{~h}$ after administering 2-HOBA acetate orally in capsules to participants. Though this study did not include a placebo control, staff nurses and participants were blinded to the capsule dosage content. Subjects were monitored at protocol-defined intervals for $24 \mathrm{~h}$ after administration of 2-HOBA. Safety assessments included vital signs (heart rate, respiration rate, blood pressure, and $\mathrm{SpO}_{2}$ ), clinical laboratory parameters (blood biochemistry, hematology, and urinalysis), 12-lead ECGs, and potential adverse event assessments. All adverse events were recorded, regardless of whether they were considered to be study-related.

\section{Pharmacokinetic sampling and analysis}

Blood samples for pharmacokinetic analyses were collected at baseline, $0.5,1,2,4,8$, and $24 \mathrm{~h}$ after 2-HOBA acetate administration for all dose levels. A 0.25-h sample was only collected for dosages $\leq 200 \mathrm{mg}$, and a 6 -h sample was only collected for dosages $\geq 330 \mathrm{mg}$. Plasma concentrations of 2-HOBA as well as the primary metabolite of 2-HOBA, salicylic acid, were determined for each time point.

$\left[{ }^{2} \mathrm{H}_{4}\right]$-2-HOBA, prepared by Dr. Venkataraman Amarnath as previously described [11], was used as an internal standard. An internal standard solution (100 ng/ $\mathrm{mL})$ of $\left(\left[{ }^{2} \mathrm{H}_{4}\right]-2-\mathrm{HOBA}\right.$ was prepared in acetonitrile and added to all standards, quality control samples, and patient samples. Standard and quality control samples of 1 $\mathrm{mg} / \mathrm{mL} 2$-HOBA were prepared in water. Eight standard curve samples $(5,10,20,100,200,1000,2000$, and 5000 $\mathrm{ng} / \mathrm{mL}$ ) were prepared with blank human plasma (Bioreclamation, Westbury, NY). In addition, three quality control samples $(15,300$, and $3000 \mathrm{ng} / \mathrm{mL})$ were prepared in blank human plasma. Plasma samples were allowed to thaw at room temperature and then vortexed. Internal standard solution $(400 \mu \mathrm{L})$ and $100 \mu \mathrm{L}$ of either plasma, quality controls, or standards were added and mixed in a protein precipitation filter 96 -well plate (Phenomenex, Torrance, CA). The solution was eluted into a 96-well plate using a positive pressure manifold and then dried under nitrogen gas at $40{ }^{\circ} \mathrm{C}$. The samples were 
then reconstituted in $97 / 3 \mathrm{v} / \mathrm{v}$ water/acetonitrile with 10 $\mathrm{mM}$ ammonium formate for analysis. Liquid chromatography tandem mass spectrometry analysis of 2-HOBA was performed with Shimadzu Nexera X2 LC-30 AD pumps, column oven, and degasser (Kyoto, Japan) (column: C18 $2.1 \times 50 \mathrm{~mm}, 1.7 \mu \mathrm{m}$, Phenomenex, Torrance, CA) coupled with a Sciex QTrap 5500 mass spectrometer with TurboV ion source (Framingham, MA). Quantification of 2-HOBA was performed using electrospray ionization in positive ionization mode. The column temperature was set to $60{ }^{\circ} \mathrm{C}$ and the flow rate was 0.5 $\mathrm{mL} / \mathrm{min}$. A gradient of $3-90 \% \mathrm{~B}$ from 0 to $0.90 \mathrm{~min}$ was established by using a mobile phase A of $10 \mathrm{mM}$ ammonium formate in water and mobile phase $\mathrm{B}$ of $1 \%$ formic acid in acetonitrile. Quantification of 2-HOBA was validated over the range of $5-5000 \mathrm{ng} / \mathrm{mL}$, with within-run precision of $3.7-7.0 \%$, bias $-9.7-2.8$ and between run precision of $4.4-6.2 \%$, bias $-7.1-1.64$. All standards and quality control samples met acceptance criteria (standard curve $\mathrm{R}^{2}>0.90,66.7 \%$ of all QC samples and at least $50 \%$ at each concentration within $15 \%$ of nominal concentration).

Plasma concentration-time data was imported into Phoenix WinNonlin ${ }^{\circ} 8.0$ software (Certara USA, Inc., Princeton, $\mathrm{NJ})$ to estimate the oral pharmacokinetic parameters of 2-HOBA from individual subjects at each dose level. Non-compartmental analysis using Model 200 (Plasma; Single Extravascular Dose; Linear Log Trapezoidal Method) was performed on each plasma concentration-time profile to estimate individual pharmacokinetic parameters half-life, area under the concentration-time curve (AUC), maximum observed plasma concentration (Cmax), and the time to reach the maximum observed plasma concentration (Tmax).

\section{Statistical analyses}

Descriptive statistics (means, standard deviations, standard error) were used for demographics, safety, and pharmacokinetic assessments.

\section{Results}

\section{Study population}

A total of 18 volunteers were enrolled in and successfully completed the study (3 subjects at each dose level). Subject demographics are provided in Table 1 and were similar across dose groups.

\section{Safety}

All reported adverse events are summarized in Table 2. Five participants (28\%) reported at least 1 adverse event during the study. The most common reported adverse event ( 2 incidences) was frequent urination (2 subjects, $11 \%)$. All adverse events were mild in intensity. No adverse events were determined to be study-related, and there was no dose-dependent increase in adverse event frequency or severity. No clinically significant changes in ECG recordings, vital signs, or laboratory parameters that were considered to be related to 2-HOBA were observed. There were no serious adverse events or deaths.

\section{Pharmacokinetics}

Mean 2-HOBA plasma concentration-time profiles and pharmacokinetic parameter estimates are shown in Fig. 1 and Table 3, respectively. Following oral administration of single doses of 2-HOBA, dose-dependent changes were observed for maximal plasma concentration $\left(\mathrm{C}_{\max }\right)$ and area under the concentration-time curve (AUC). The mean time to reach $\mathrm{C}_{\max }$ was $1.6 \mathrm{~h}$ and the mean half-life of 2-HOBA was $2.1 \mathrm{~h}$.

Table 1 Demographic Characteristics

\begin{tabular}{|c|c|c|c|c|c|c|c|}
\hline & \multicolumn{6}{|c|}{ 2-Hydroxybenzylamine acetate dose } & \multirow[b]{2}{*}{ Total } \\
\hline & $50 \mathrm{mg}$ & $100 \mathrm{mg}$ & $200 \mathrm{mg}$ & $330 \mathrm{mg}$ & $550 \mathrm{mg}$ & $825 \mathrm{mg}$ & \\
\hline Volunteers $(n)$ & 3 & 3 & 3 & 3 & 3 & 3 & 18 \\
\hline Sex: female $[n(\%)]$ & $2(66.7)$ & $1(33.3)$ & $0(0)$ & $3(100)$ & $1(33.3)$ & $2(66.7)$ & $9(50.0)$ \\
\hline Age (y) & $25.7 \pm 2.1$ & $32.7 \pm 6.4$ & $27.7 \pm 5.7$ & $26.3 \pm 4.0$ & $28.0 \pm 6.0$ & $23.0 \pm 2.6$ & $27.2 \pm 5.0$ \\
\hline Height $(\mathrm{cm})$ & $174.3 \pm 7.6$ & $184.6 \pm 11.7$ & $174.2 \pm 4.0$ & $165.7 \pm 6.8$ & $175.7 \pm 17.8$ & $160.4 \pm 5.6$ & $172.5 \pm 11.6$ \\
\hline Weight (kg) & $60.7 \pm 2.1$ & $95.0 \pm 37.0$ & $83.3 \pm 30.6$ & $60.0 \pm 8.0$ & $87.7 \pm 33.8$ & $68.3 \pm 14.2$ & $75.8 \pm 25.1$ \\
\hline $\operatorname{BMI}\left(\mathrm{kg} / \mathrm{m}^{2}\right)$ & $20.1 \pm 2.3$ & $27.3 \pm 7.8$ & $27.2 \pm 8.8$ & $21.8 \pm 1.3$ & $27.5 \pm 5.0$ & $26.4 \pm 3.8$ & $25.0 \pm 5.6$ \\
\hline \multicolumn{8}{|l|}{ Race } \\
\hline Hawaiian/Pacific Islander & $0(0)$ & $0(0)$ & $0(0)$ & $0(0)$ & $1(33.3)$ & $0(0)$ & $1(5.5)$ \\
\hline White & $3(100)$ & $3(100)$ & $3(100)$ & $3(100)$ & $2(66.7)$ & $3(100)$ & $17(94.4)$ \\
\hline \multicolumn{8}{|l|}{ Ethnicity } \\
\hline Hispanic/Latino & $0(0)$ & $0(0)$ & $0(0)$ & $0(0)$ & 1 (33.3) & $0(0)$ & $1(5.5)$ \\
\hline Not Hispanic/Latino & $3(100)$ & $3(100)$ & $3(100)$ & $3(100)$ & $2(66.7)$ & $3(100)$ & $17(94.4)$ \\
\hline
\end{tabular}

Data are presented as means \pm SD unless otherwise noted 
Table 2 Summary of reported adverse events by dose

\begin{tabular}{|c|c|c|c|c|c|c|c|}
\hline & \multicolumn{6}{|c|}{ 2-Hydroxybenzylamine acetate dose } & \multirow{2}{*}{$\begin{array}{l}\text { Total } \\
(n=18)\end{array}$} \\
\hline & $50 \mathrm{mg}(n=3)$ & $100 \mathrm{mg}(n=3)$ & $200 \mathrm{mg}(n=3)$ & $330 \mathrm{mg}(n=3)$ & $550 \mathrm{mg}(n=3)$ & $825 \mathrm{mg}(n=3)$ & \\
\hline Any event, $\mathrm{n}(\%)$ & $3(100)$ & 0 & $1(33)$ & $1(33)$ & 0 & 0 & $5(28)$ \\
\hline Frequent urination & $2(67)$ & 0 & 0 & 0 & 0 & 0 & $2(11)$ \\
\hline Headache & 0 & 0 & $1(33)$ & 0 & 0 & 0 & $1(5.5)$ \\
\hline Itchy throat & $1(33)$ & 0 & 0 & 0 & 0 & 0 & $1(5.5)$ \\
\hline Rash & $1(33)$ & 0 & 0 & 0 & 0 & 0 & $1(5.5)$ \\
\hline Sleepiness & $1(33)$ & 0 & 0 & 0 & 0 & 0 & $1(5.5)$ \\
\hline Abdominal bloating & 0 & 0 & 0 & $1(33)$ & 0 & 0 & $1(5.5)$ \\
\hline
\end{tabular}

Plasma concentrations of the primary metabolite of 2-HOBA, salicylic acid were also measured. Systemic exposure to salicylic acid following oral administration of single doses of 2-HOBA acetate at each dose level is shown in Additional file 1: Figure S1 and quantified in Additional file 1: Table S1, both located in Additional file 1. Following oral administration of 2-HOBA, dose-dependent changes were observed in the systemic exposure $\left(C_{\max }\right.$ and AUC) of salicylic acid. The $t_{\max }$ for salicylic acid ranged from 2.67 to $4.67 \mathrm{~h}$ and tended to increase as the 2-HOBA dose increased.

\section{Discussion}

The results of this first-in-human study demonstrate that single doses of 2-HOBA acetate up to $825 \mathrm{mg}$ were well tolerated by healthy individuals. No serious adverse events or dose-limiting adverse events were observed.
All reported adverse events were mild in intensity and unlikely to be 2-HOBA-related. There were no clinically significant findings in vital signs, ECG recordings, or clinical laboratory parameters.

After oral administration of a single dose, 2-HOBA was readily absorbed, with a $t_{\max }$ of 1 to $2 \mathrm{~h}$ after administration at all dose levels. Systemic exposure to 2-HOBA was dose-dependent, as was the exposure of salicylic acid, the primary metabolite of 2-HOBA. The pharmacokinetic values for salicylic acid observed in this study were similar to those observed after single doses of 40.5-324 mg of acetylsalicylic acid (aspirin) [18], which is rapidly hydrolyzed to salicylic acid after oral administration. This suggests the tested dose range of 2-HOBA acetate induces similar salicylic acid exposure to that observed with low-to-moderate doses of acetylsalicylic acid.

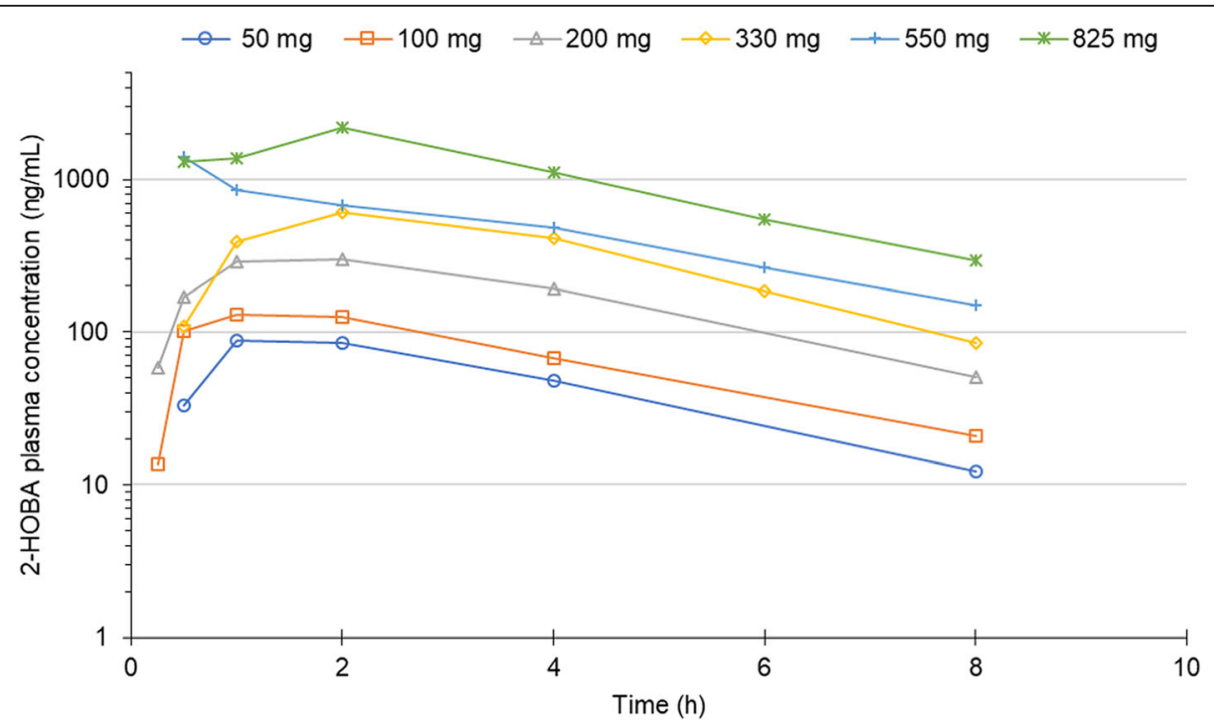

Fig. 1 2-Hydroxybenzylamine (2-HOBA) plasma concentrations after oral administration of 2-HOBA acetate. 2-HOBA plasma concentration was measured for $24 \mathrm{~h}$ after oral administration of six ascending single doses of 2-HOBA acetate in healthy subjects ( $\mathrm{n}=3$ per dose level). Blood samples for pharmacokinetic analyses were collected at baseline, 0.5, 1, 2, 4, 8, and $24 \mathrm{~h}$ after 2-HOBA acetate administration for all dose levels. A 0.25 -hour sample was only collected for dosages $\leq 200 \mathrm{mg}$, and a 6 -h sample was only collected for dosages $\geq 330 \mathrm{mg}$. No 2-HOBA was detectable prior to administration (time 0 ) or at $24 \mathrm{~h}$ post-administration (assay limit of detection $=5 \mathrm{ng} / \mathrm{mL}$ ) 
Table 3 Mean 2-hydroxybenzylamine pharmacokinetic parameters after a single oral dose

\begin{tabular}{|c|c|c|c|c|c|c|}
\hline \multirow[t]{2}{*}{ Parameter } & \multicolumn{6}{|c|}{ 2-Hydroxybenzylamine acetate dose } \\
\hline & $50 \mathrm{mg}(n=3)$ & $100 \mathrm{mg}(n=3)$ & $200 \mathrm{mg}(n=3)$ & $330 \mathrm{mg}(n=3)$ & $550 \mathrm{mg}(n=3)$ & $825 \mathrm{mg}(n=3)$ \\
\hline Half-life (h) & 2.04 & 2.33 & 2.03 & 1.77 & 2.32 & 2.13 \\
\hline$C_{\max }(n g / m L)$ & 90 & 156 & 369 & 669 & 1636 & 2510 \\
\hline$t_{\max }(h)$ & 1.33 & 1.33 & 1.83 & 1.67 & 1.67 & 1.67 \\
\hline $\mathrm{AUC}(\mathrm{h} \cdot \mathrm{ng} / \mathrm{mL})$ & 396 & 622 & 1490 & 2690 & 4417 & 9053 \\
\hline$A \cup C_{\text {extrap }}(\%)$ & 9.1 & 11.2 & 10.0 & 8.2 & 11.2 & 10.3 \\
\hline
\end{tabular}

$C_{\max }$ maximum observed plasma concentration, $t_{\max }$ time to reach, $C_{\max } \mathrm{AUC}$, area under the concentration-time curve from zero to infinity, $A \cup C_{\text {extrap }}$ percentage of the AUC extrapolated from the last observed time point

Clearance and volume of distribution are not reported due to the unknown value of $F$ (bioavailability)

The terminal slopes of the log-linear phase of the plasma-concentration time profiles for 2-HOBA were parallel and independent of dose, which is reflected in the similar half-life at each dose level. 2-HOBA appears to have a relatively short half-life $(\sim 2 \mathrm{~h})$. These pharmacokinetic properties of 2-HOBA in humans are generally similar to those previously observed in mice [11]. Clearance and volume of distribution are not reported due to the unknown value of $\mathrm{F}$ (bioavailability) following oral administration of 2-HOBA acetate.

These observations supporting that orally administered 2-HOBA acetate is well-tolerated and safe in humans comprise an important addition to our portfolio of preclinical 2-HOBA safety data. The good safety profile to date combined with the preclinical efficacy established in mice at risk for age-related cognitive decline support continued development of 2-HOBA as a nutritional supplement to enhance cognitive health and support healthy brain aging. Additionally, although our development of 2-HOBA has been primarily focused on the cognitive decline associated with Mild Cognitive Impairment or Alzheimer's disease, there is also evidence for beneficial effects of 2-HOBA on other aspects of neurological health associated with the accumulation of dicarbonyl adducts, such as seizure-associated cognitive dysfunction. 2-HOBA attenuated neuronal loss, astrogliosis, and spatial and reference memory deficits in mouse models of epilepsy without affecting epileptic injury [19].

There is also evidence for beneficial effects of 2-HOBA on cardiovascular health, most notably blood pressure. 2-HOBA attenuated angiotensin-II induced hypertension and renal damage in mice [5], normalized blood pressure in a murine model of hypertension [20], and prevented the development of pulmonary arterial hypertension in mice with mitochondrial oxidant injury [21]. Exposure to 2-HOBA also attenuated molecular aging and extended longevity in C. elegans, increasing lifespan by more than $50 \%$ [22]. Together, these additional preclinical studies support the potential for 2-HOBA to have wide-ranging protective effects against oxidant-related disease and dysfunction.
A limitation of this first-in-human study is the relatively narrow age range of volunteers. Though older individuals were not excluded from participation in this trial, the enrolled cohort ranged in age from 20 to 40 years; this limits the generalizability of these findings to broader populations. Follow-up studies should specifically target older individuals to identify any unique adverse effects or pharmacokinetic properties in this population.

\section{Conclusions}

In summary, 2-HOBA acetate was safe and well-tolerated in single dose administration up to $825 \mathrm{mg}$ in healthy human volunteers. The pharmacokinetic profile was reasonable, exhibiting fairly rapid absorption and elimination of 2-HOBA. Next steps include evaluating the safety and tolerability of multiple doses of 2-HOBA acetate in healthy individuals as well as older individuals more representative of the population segment at elevated risk for developing Alzheimer's disease. We will also confirm in humans that 2-HOBA crosses the blood brain barrier, as has been previously demonstrated in rodents [11].

\section{Additional file}

Additional file 1: Figure S1 and Table S1. Mean exposure and pharmacokinetics of the primary metabolite of 2-HOBA, salicylic acid, after oral administration of 2-HOBA acetate. (DOCX $21 \mathrm{~kb}$ )

Abbreviation

2-HOBA: 2-hydroxybenzylamine

Funding

The study was supported by the National Institute On Aging of the National Institutes of Health under Award Number AG055184 and by CTSA award Number UL1 TR002243 from the National Center for Advancing Translational Sciences.

Availability of data and materials

The data for this research study was collected under informed consent of the volunteers. Thus, access to the data will be subject to approval by the Vanderbilt University Medical Center Institutional Review Board.

\section{Authors' contributions}

JAR, JCF, NNA, VA, LJR, JAO, and OB contributed to the conception and design of the study. PMC, JAO, and $\mathrm{OB}$ collected and/or interpreted the 
clinical data. JSD, RDM, and WSA performed and interpreted the pharmacokinetic analyses. LMP and JAR drafted the manuscript. JCF, JSD, WSA, NNA, JAO, and OB critically revised the manuscript. All authors read and approved the final manuscript.

\section{Ethics approval and consent to participate}

The study protocol was approved by the Vanderbilt University Institutional Review Board. All participants provided written informed consent before participating in the study.

\section{Consent for publication}

Not applicable.

\section{Competing interests}

JCF, LMP, and JAR are employed by and NNA is co-founder and part owner of Metabolic Technologies, Inc., which has executed an agreement for the rights to license the intellectual property for 2-hydroxybenzylamine from Vanderbilt University. JSD and RDM are employed by Sano Informed Prescribing, which received payment for services provided for this study. WSA received payment for the clinical pharmacokinetic analysis.

\section{Publisher's Note}

Springer Nature remains neutral with regard to jurisdictional claims in published maps and institutional affiliations.

\section{Author details}

${ }^{1}$ Metabolic Technologies, Inc., Ames, IA 50010, USA. ${ }^{2}$ Department of Animal Science, lowa State University, Ames, IA 50010, USA. ${ }^{3}$ Sano Informed Prescribing Inc., Franklin, TN 37067, USA. ${ }^{4}$ Department of Pharmaceutical Sciences, Lipscomb University College of Pharmacy, Nashville, TN 37204, USA. ${ }^{5}$ Department of Pharmacology, Division of Clinical Pharmacology, Vanderbilt University, Nashville, TN 37232, USA. ${ }^{6}$ Department of Surgery, Vanderbilt University Medical Center, Nashville, TN 37232, USA. ${ }^{7}$ Department of Medicine, Division of Clinical Pharmacology, Vanderbilt University Medical Center, Nashville, TN 37232, USA. ${ }^{8}$ Department of Medicine, Division of Clinical Pharmacology, Vanderbilt University Medical Center, Nashville, TN 37232, USA.

Received: 10 September 2018 Accepted: 20 December 2018 Published online: 05 January 2019

\section{References}

1. Roberts $L$, Salomon RG, Morrow JD, Brame CJ. New developments in the isoprostane pathway: identification of novel highly reactive gammaketoaldehydes (isolevuglandins) and characterization of their protein adducts. FASEB J. 1999;13(10):1157-68.

2. Salomon RG, Miller DB, Zagorski MG, Coughlin DJ. Solvent-induced fragmentation of prostaglandin endoperoxides. New aldehyde products from PGH2 and a novel intramolecular 1,2-hydride shift during endoperoxide fragmentation in aqueous solution. J Am Chem Soc. 1984;106:6049-60.

3. Zagol-Ikapitte I, Masterson TS, Amarnath V, Montine TJ, Andreasson KI, Boutaud $\mathrm{O}$, et al. Prostaglandin H(2)-derived adducts of proteins correlate with Alzheimer's disease severity. J Neurochem. 2005;94(4):1140-5.

4. Bernoud-Hubac N, Alam DA, Lefils J, Davies SS, Amarnath V, Guichardant M, et al. Low concentrations of reactive gamma-ketoaldehydes prime thromboxane-dependent human platelet aggregation via p38-MAPK activation. Biochim Biophys Acta. 2009;1791(4):307-13.

5. Kirabo A, Fontana V, de Faria AP, Loperena R, Galindo CL, Wu J, et al. DC isoketal-modified proteins activate T cells and promote hypertension. J Clin Invest. 2014;124(10):4642-56.

6. Roychowdhury S, McMullen MR, Pritchard MT, Li W, Salomon RG, Nagy LE. Formation of gamma-ketoaldehyde-protein adducts during ethanol-induced liver injury in mice. Free Radic Biol Med. 2009;47(11):1526-38.

7. Boutaud O, Ou JJ, Chaurand P, Caprioli RM, Montine TJ, Oates JA. Prostaglandin $\mathrm{H} 2$ (PGH2) accelerates formation of amyloid beta1-42 oligomers. J Neurochem. 2002;82(4):1003-6.

8. Boutaud O, Montine TJ, Chang L, Klein WL, Oates JA. PGH2-derived levuglandin adducts increase the neurotoxicity of amyloid beta1-42. J Neurochem. 2006;96(4):917-23.
9. Zagol-Ikapitte I, Amarnath V, Bala M, Roberts $\sqcup$, Oates JA, Boutaud O. Characterization of scavengers of gamma-ketoaldehydes that do not inhibit prostaglandin biosynthesis. Chem Res Toxicol. 2010;23(1):240-50.

10. Koyama M, Obata Y, Sakamura S. Identification of hydroxybenzylamines in buckwheat seeds. Agri Biol Chem. 1971;35:1870-9.

11. Zagol-Ikapitte IA, Matafonova E, Amarnath V, Bodine CL, Boutaud O, Tirona $\mathrm{RG}$, et al. Determination of the pharmacokinetics and Oral bioavailability of Salicylamine, a potent gamma-Ketoaldehyde scavenger, by LC/MS/MS. Pharmaceutics. 2010;2(1):18-29.

12. Davies SS, Bodine C, Matafonova E, Pantazides BG, Bernoud-Hubac N, Harrison FE, et al. Treatment with a gamma-ketoaldehyde scavenger prevents working memory deficits in hApoE4 mice. J Alzheimers Dis. 2011; 27(1):49-59.

13. Pitchford LM, Smith JD, Abumrad NN, Rathmacher JA, Fuller JC Jr. Acute and 28-day repeated dose toxicity evaluations of 2-hydroxybenzylamine acetate in mice and rats. Regul Toxicol Pharmacol. 2018.

14. Fuller JC, Pitchford LM, Morrison RD, Daniels JS, Flynn CR, Abumrad NN, et al. In vitro safety pharmacology evaluation of 2-hydroxybenzylamine acetate. Food Chem Toxicol. 2018;121:541-548.

15. Fuller JC, Pitchford LM, Abumrad NN, Rathmacher JA. Subchronic (90-day) repeated dose toxicity study of 2-hydroxybenzylamine acetate in rats. Regulatory Toxicology and Pharmacology. 2018;99:225-232.

16. Fuller JC, Pitchford LM, Abumrad NN, Rathmacher JA. Subchronic (90-day) repeated dose oral toxicity study of 2-hydroxybenzylamine acetate in rabbit. Regul Toxicol Pharmacol. 2018;100:52-58.

17. Rogatko A, Schoeneck D, Jonas W, Tighiouart M, Khuri FR, Porter A. Translation of innovative designs into phase I trials. J Clin Oncol. 2007; 25(31):4982-6.

18. MTt R, Krishnan $K$, Rock CL, Normolle D, Vaerten MA, Peters-Golden M, et al. Suppression of human colorectal mucosal prostaglandins: determining the lowest effective aspirin dose. J Natl Cancer Inst. 1997;89(15):1152-60.

19. Pearson JN, Warren E, Liang LP, Roberts $L J$ 2nd, Patel M. Scavenging of highly reactive gamma-ketoaldehydes attenuates cognitive dysfunction associated with epileptogenesis. Neurobiol Dis. 2017;98:88-99.

20. Wu J, Saleh MA, Kirabo A, Itani HA, Montaniel KR, Xiao L, et al. Immune activation caused by vascular oxidation promotes fibrosis and hypertension. J Clin Invest. 2016;126(1):50-67.

21. Egnatchik RA, Brittain EL, Shah AT, Fares WH, Ford HJ, Monahan K, et al. Dysfunctional BMPR2 signaling drives an abnormal endothelial requirement for glutamine in pulmonary arterial hypertension. Pulm Circ. 2017;7(1):186-99.

22. Nguyen TT, Caito SW, Zackert WE, West JD, Zhu S, Aschner M, et al. Scavengers of reactive gamma-ketoaldehydes extend Caenorhabditis elegans lifespan and healthspan through protein-level interactions with SIR-2.1 and ETS-7. Aging (Albany NY). 2016;8(8):1759-80.

Ready to submit your research? Choose BMC and benefit from:

- fast, convenient online submission

- thorough peer review by experienced researchers in your field

- rapid publication on acceptance

- support for research data, including large and complex data types

- gold Open Access which fosters wider collaboration and increased citations

- maximum visibility for your research: over 100M website views per year

At BMC, research is always in progress.

Learn more biomedcentral.com/submissions 